\title{
Detection of MTHFR (A1298C) Gene Polymorphism in Women Suffer from Different Types of Abortion in Mosul City
}

\author{
Zahra J. Ramadan ${ }^{1}$, Owayes M. Hamed ${ }^{2 *}$ \\ ${ }^{1,2}$ Department of Biology, College of Science, University of Mosul, Mosul, Iraq \\ E-mail: ${ }^{1}$ Zahra.jasem2018@ gmail.com, ${ }^{2 *}$ Owsbio31@ uomosul.edu.iq
}

(Received April 13, 2020; Accepted May 16, 2020; Available online September 01, 2020)

DOI: 10.33899/edusj.2020.126923.1064, (c) 2020, College of Education for Pure Science, University of Mosul.

This is an open access article under the CC BY 4.0 license (http://creativecommons.org/licenses/by/4.0/).

\begin{abstract}
:
Genetic basis of recurrent abortion is poorly understood, Single gene mutations, polygenic, and cytogenetic factors are all found to show association with recurrent abortion. The analysis of single nucleotide polymorphisms in the genes coding for enzymes which responsible for regulatory of metabolic pathways (e.g. methylene tetra hydrofolate reductase), clotting factors (Factor V leiden and prothrombin) and hormones and hormone receptors (progesterone receptor). This study included (85) pregnant women who suffer from problems during pregnancy and the age range was between (25-35) years. The samples were divided into four groups ,the first included pregnant women who suffer from recurrent spontaneous abortion, while the second included pregnant women with missed abortion, the third group included pregnant women with recurrent spontaneous abortion and positive TORCH examination and the final group was considered a control group.

The result of the study showed a relationship between cases of pregnancy disorder and genetic mutations of MTHFR gene at the (A1298C) site, the result of the study for a group of women with RSA showed that the distribution of the mutant genotype CC was the highest $40 \%$ and the repetitive alleles for this group was $57.5 \%$ for mutant allele $\mathrm{C}$ and $42.5 \%$ for normal allele A.

Also the group of missed abortion showed that the distribution of the mutant genotype CC was the highest $40 \%$ and the repetitive alleles for this group was $52.5 \%$ for mutant allele $\mathrm{C}$ and $47.5 \%$ for normal allele A.

Whereas the group of women with positive TORCH showed that the distribution of heterozygous genotype was the highest $50 \%$ and the repetitive alleles for this group was $32.2 \%$ for mutant allele $\mathrm{C}$ and $67.8 \%$ for normal allele $\mathrm{A}$.
\end{abstract}

Key words: Abortion, MTHFR gene, gene polymorphism, Mutation.

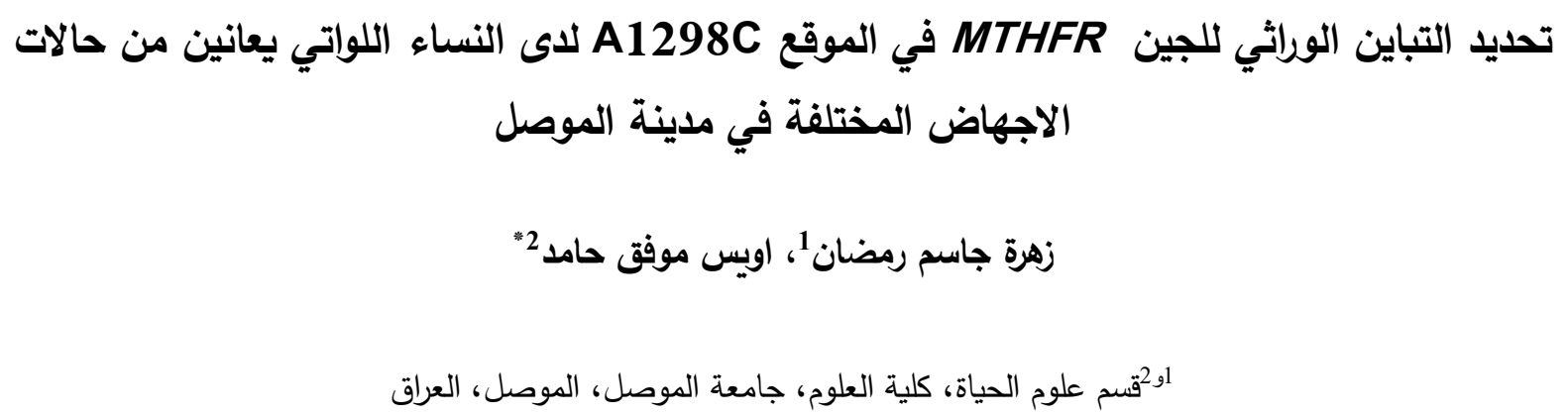


إن الأساس الوراثي لحالات الاجهاض المتكرر يكون غير واضح جدا اذ ان الطفرات الجينية وحالات التعدد الجيني وعوامل الوراثة الخلوية جميعها وجدت مترابطة مع حالات الاجهاض المتكرر ولتفسير بعض حالات الاجهاض المتكرر فقد تم تحليل التباينات الوراثية SNP single nencleotied polymeorphism في عدة عوامل منها الجينات المشفرة للإنزيمات التي تتضم الفعالية

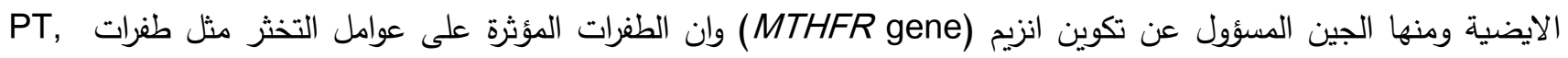
FVL والطفرات المؤثرة على انتاج الهرمونات او المؤثرة على مستقبلات مثل مستقبلات بروجستيرون.

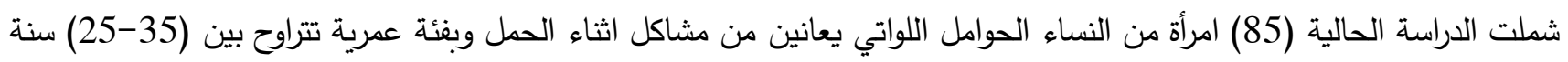

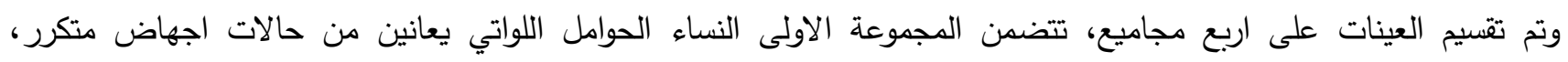

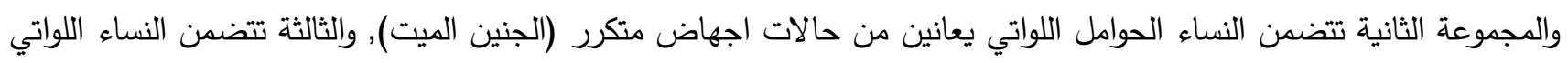

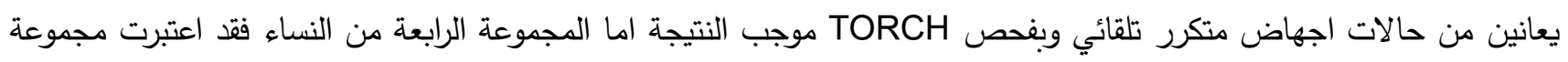
سيطرة، تم سحب (5) مل من الدم الوريدي من النساء وتم تقسيمه على جزأين، الجزء الاول تم وضعاله في انابيب تحتوي على ملى مادة

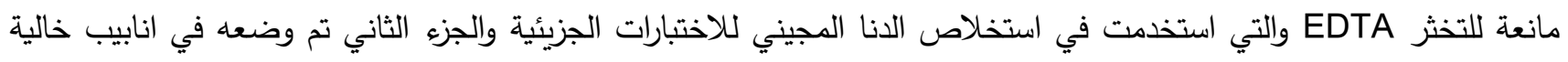
من مانع التخثر لاجراء الاختبارات الكيموحيوية.

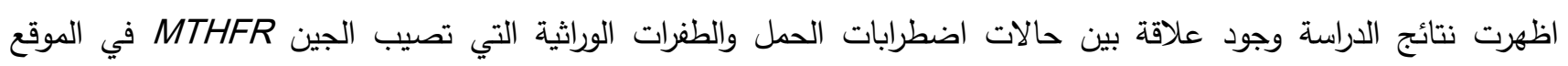
A1298C إذ اظهرت نتائج الدراسة لمجموعة النساء اللواتي يعانين من الاجهاض المتكرر بان نسبة توزيع الطراز الوراثي الطافر

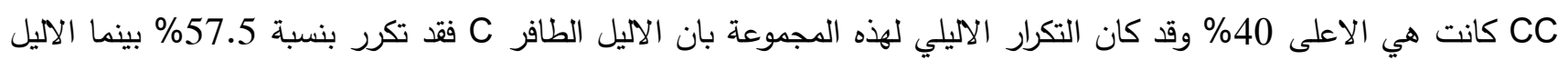
الطبيعي A فقد تكرر بنسبة 42.5\%. في حين اظهرت النسب لمجموعة النساء اللواتي يعانين من حالات الجنين الميت بان نسبة لطانية توزيع الطراز الوراثي الطافر CC ايضا كانت هي الاعلى 40\% الطا التكرار الاليلي فقد بينت الدراسة لهذه المجموعة بان بان الاليل

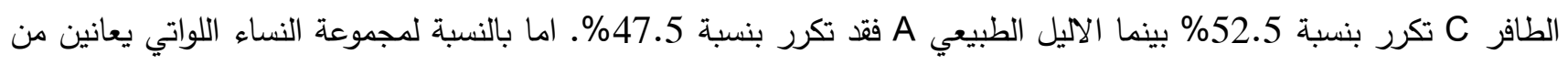

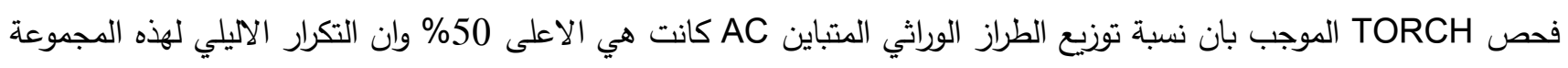

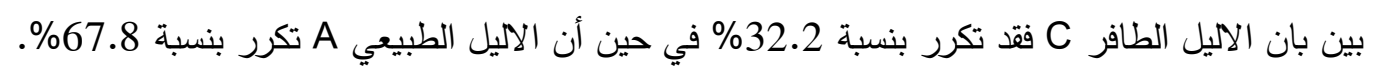

الكلمات المفتاحية: الاجهاض, الطفرات, التباين الوراثي, الجين MTHFR

المقدمة

تعاني النساء الحوامل من مشاكل واضطرابات كثيرة خلال فترة الحمل ويعتبر الاجهاض المشكلة الاكثر تعقيدا وشيوعا في الحمل اذ

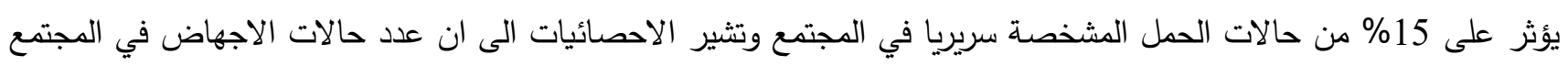
تكون اكبر من عدد حالات الحمل الفعلي [1,2]. ان الاساس الوراثي لحالات الاجهاض المتكرر يكون غير واضح جدا حيث ان الطفرات الجينية وحالات التباين الوراثي وعوامل الوراثة الخلوية جميعها وجدت مترابطة مع حالات الاجهاض المتكرر ولتفسير هذه الحالات وان الطفرات المؤثرة على عوامل التخثر مثل الطفرات التي تصيب جينات عوامل التخثر ومنها Factor V Lieden و جين Prothrombin والطفرات المؤثرة على انتاج الهرمونات او المؤثرة على مستقبلات الهرمونات مثل مستقبلات هرمون بروجستيرون [3]. يعتبر جين MTHFR المسؤول عن تكوين انزيم methylene tetra hydro folatereductase وهو انزيم أساس يحفز تحويل 5-methylen tetra hydrofolate 5,10-methylen tetra hydrofolate وهو الثكل المنتشر والسائد للفوليت ويشارك 
في عملية مثيلة الهوموستتين (المعتمدة على فيتامين B12 ) الى الميثونين الذي بدوره يتحول الى S-adenosyl-methionine والذي يعمل كواهب لمجموعة المثيل في عملية مثيلة ال DNA والبروتينات والنواقل العصبية والدهون المفنفرة وان التباين الجيني لـئي

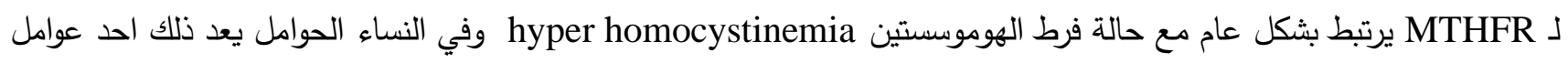

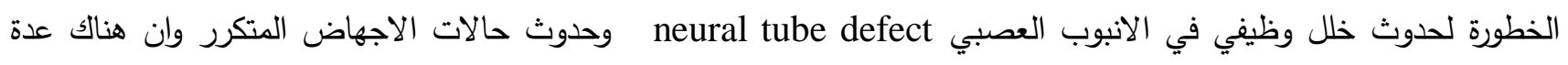
دراسات سجلت الترابط بين زيادة مستوى الهوموستين مع حالات فقدان الحمل المبكر الاول ويوجد نوعان من التغايير الوراثي في ولاتي

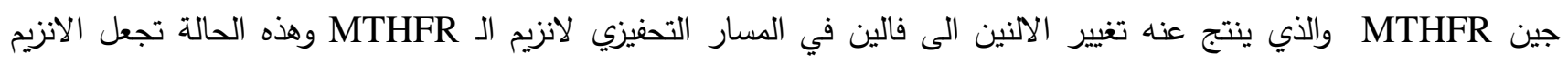
عرضة للتلف وتقلل من فعاليته [4,5,6,7].

كذلك تعتبر متلازمة الاجسام المضادة للدهون المفنفرة من مسببات الاجهاض اذ تكون هذه المتلازمات كاضطراب في النظام المناعي يتميز بحدوث زيادة او فرط في تخثر الدم ومضاعفات اخرى لاى النساء الحوامل (اجهاض مبكر وولادة مبكرة وموت فئره

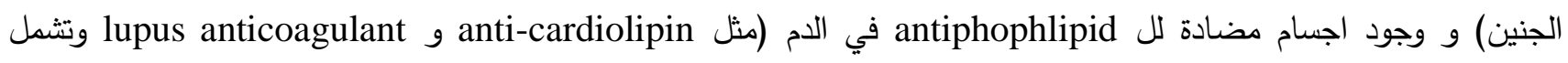
اضطرابات التخثر المرتبطة بمتلازمة الاجسام المضادة للفوسفوليبيد: الجلطة وجلطات الدم في عمق الساقين (تجلط الدم الوريدي

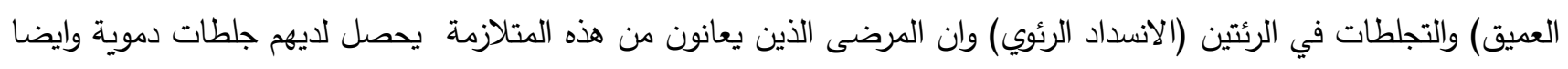

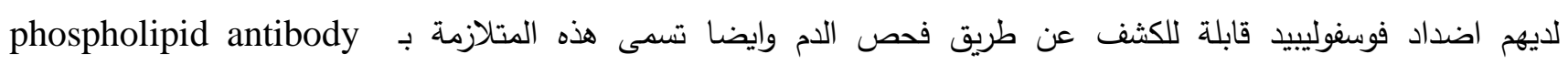

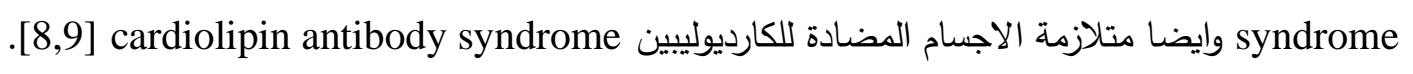
وتهدف هذه الدراسة الى تحليل التباينات الوراثية single nencleotied polymeorphism SNP في الجين MTHFR) وهو الجين المسؤول عن تكوين انزيم فئ gethylentetrahydrofolatereductase (MTHFR) gene (methylentetrahydrofolatereductase

المواد وطرائق العمل شملت الدراسة الحالية (85) امرأة من النساء الحوامل اللواتي يعانين من مشاكل اضطرابات الحمل وبنفس الفئة العمرية تتراوح بين (35-25) سنة من المراجعات الى مستثفى الخنساء التعليمي في فترة زمنية تراوحت من شهر تموز الى شهر تشرين الاول من عام

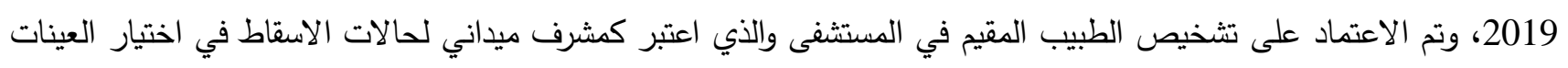

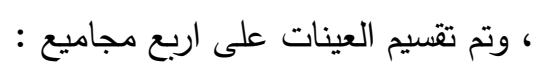
المجموعة الاولى: تتضمن هذه المجموعة 21 امرأة من النساء الحوامل اللواتي يعانين من حالات اجهاض متكرر تلقائي, المجموعة الثانية: تتضمن هذه المجموعة 30 امرأة من النساء الحوامل اللواتي يعانين من حالات اجهاض متكرعة الأهر (الجنين الميت), المجموعة

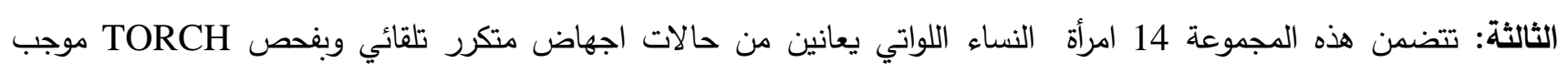
النتيجة, المجموعة الرابعة: تتضمن هذه المجموعة 20 امرأة من النساء الحوامل اللواتي لا يعانين من اي مشاكل الثاء التهاء الحمل وتم اعتمادها كمجموعة سيطرة.

\section{جمع وحفظ نماذج الدم}

تم سحب (5) مل من الدم الوريدي من النساء وتم تقسيمه على جزأين، الجزء الاول من الدم وحفظ بانابيب خالية من مانع التخثر لاجراء اختبارات متلازمة الاجسام المضادة للفوسفولبيد

ELISAl

وجزء اخر وضع في انابيب تحتوي على مادة مانعة للتخثر EDTA والتي استخدمت في استخلاص الـ DNA بالاعتماد على

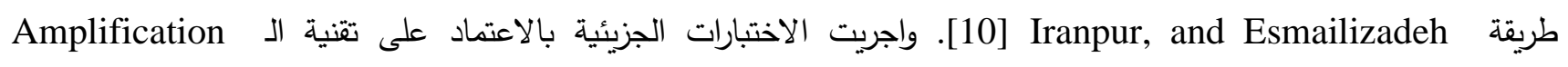




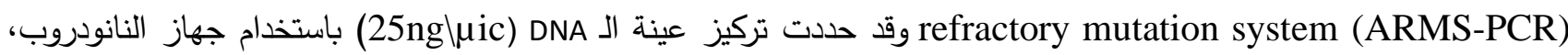
وكثف عن وجود الطفرة A 1298 Cباضافة 4 مايكروليتر وبتركيز (100) نانوغرام من الدنا القالب و 1 مايكروليتر بتركيز

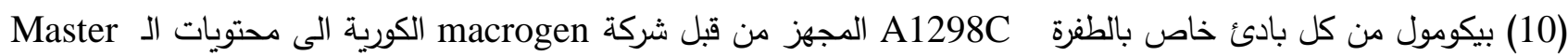
.[11].mix

\begin{tabular}{|l|l|c|c|}
\hline primer & Sequence & tm & $\begin{array}{c}\text { Band } \\
\text { size }\end{array}$ \\
\hline F-outer & GAAGAAGTTTGCATGCTTGTGGTTG & 64.0 & $593 \mathrm{bp}$ \\
\hline R-outer & CAGGCAAGTCACCTGGGAGAGA & 66.0 & \\
\hline F-inner & GGCAAAGAACGAGACTTCAAAGACACATT & 67.0 & $281 \mathrm{bp}$ \\
\hline R-inner & GAGGAGCTGACCAGTGATGC & 62.0 & $361 \mathrm{bp}$ \\
\hline
\end{tabular}

بعدها تم ادخـال انابيب التفاعل في جهاز المبلمر الحراري Thermocycler لإجراء التفاعل التضـاعفي وباستخدام

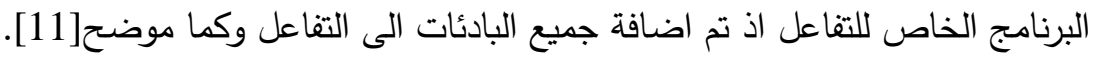

\begin{tabular}{|c|c|c|c|c|}
\hline No. & Stage & Temperature & Time & Cycle number \\
\hline 1. & Initial denaturation & 95 & $5 \mathrm{~min}$. & 1 \\
\hline 2. & denaturation & 95 & $45 \mathrm{sec}$. & \multirow{3}{*}{35} \\
\hline 3. & Annealing & 61 & $1 \mathrm{~min}$. & \\
\hline 4. & Extension & 72 & $1 \mathrm{~min}$. & \\
\hline 5. & Final extension & 72 & $7 \mathrm{~min}$. & 1 \\
\hline 6. & Stop reaction & 4 & $5 \mathrm{~min}$ & 1 \\
\hline
\end{tabular}

\section{النتائج والمناقشة}

اظهرت نتائج الدراسة كما هو موضح في الثكل (1و2) وجود علاقة بين حالات الاجهاض المتكرر والطفرات الوراثية التي تصيب

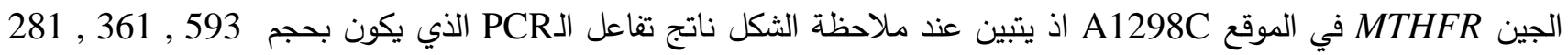
bp والتي تدل على ظهور التباين الوراثي للجين وبجميع الطرز الوراثية AA,AC,CC وبنسب مئوية مختلفة كما هو موضح في

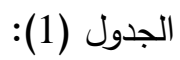




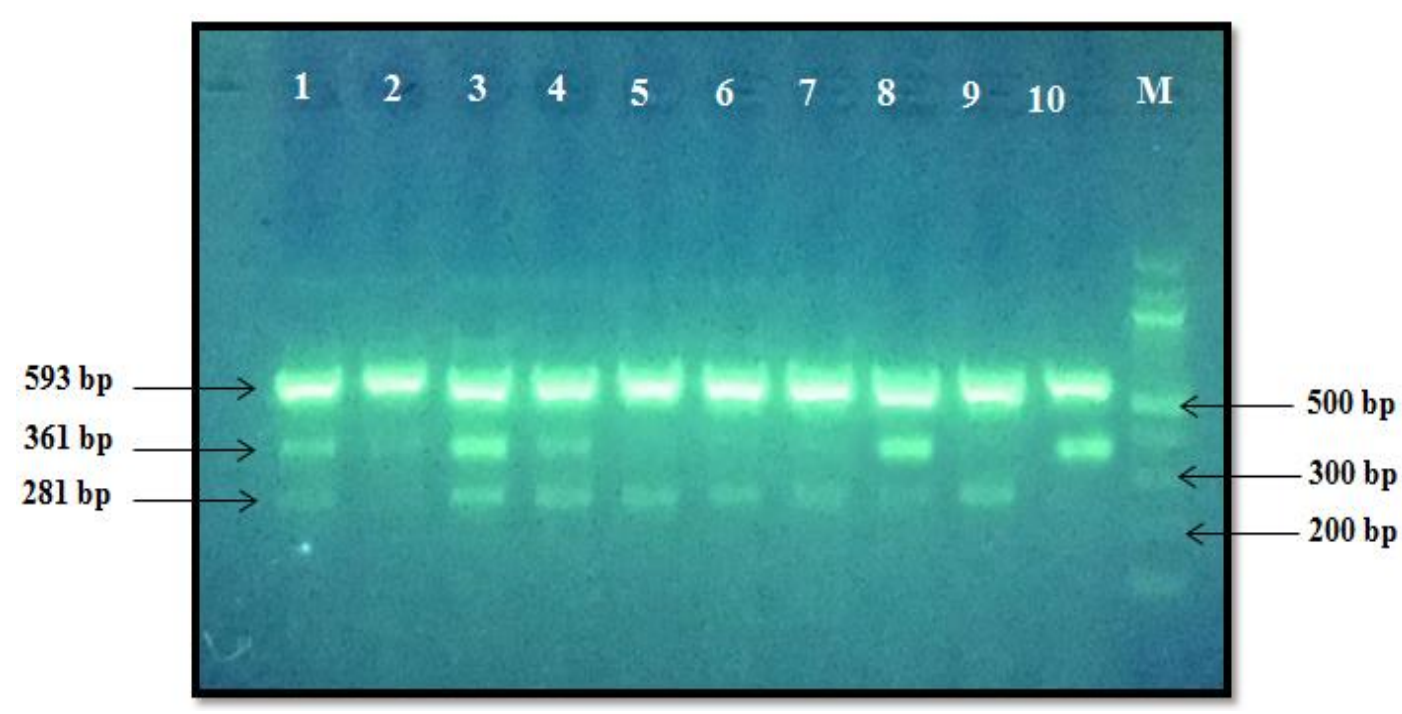

الثكل (1): تبين ناتج تفاعل الـ PCR الخاص بالتباين الوراثي للجين MTHFR (A1298C) في مجموعة النساء ذوات الجهاض المتكرر إذ إن M تمثل

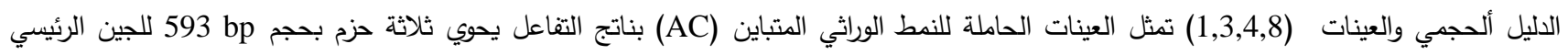

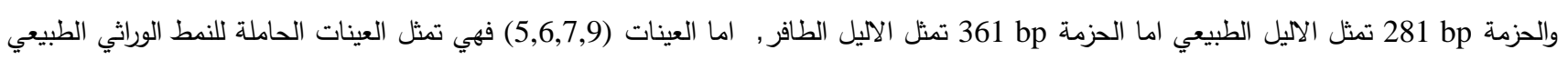

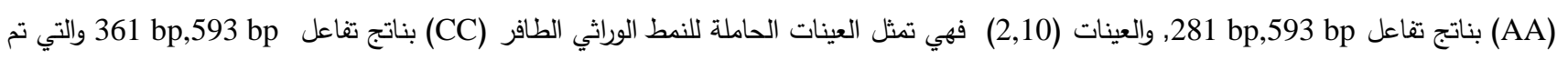
ترحيلها في هلام الاكاروز بتركيز 2.

جلول (1): توزيع النمط الوراثي ومستوى المشاهدة الاليلي للجين MTHFR في الموقع (A1298C) بين مجموعة السيطرة والنساء اللواتي يعانون من حالات الاسقاط التلقائي المتكرر .

\begin{tabular}{|c|c|c|c|c|c|c|c|}
\hline \multirow[t]{2}{*}{ Genotypes } & \multicolumn{2}{|c|}{$\begin{array}{r}\text { Patients No. } \\
\text { (20) }\end{array}$} & \multicolumn{2}{|c|}{$\begin{array}{l}\text { Control } \\
\text { No. (20) }\end{array}$} & \multirow[t]{2}{*}{$P$ value } & \multirow[t]{2}{*}{ OR } & \multirow[t]{2}{*}{$(95 \% \mathrm{CI})$} \\
\hline & No. & $\%$ & No. & $\%$ & & & \\
\hline $\mathrm{AA}$ & 5 & 25 & 14 & 70 & \multirow{3}{*}{0.1204} & Ref & \multirow{2}{*}{0.7333 to 14.5514} \\
\hline $\mathrm{AC}$ & 7 & 35 & 6 & 30 & & 3.2667 & \\
\hline $\mathbf{C C}$ & 8 & 40 & $\mathbf{0}$ & $\mathbf{0}$ & & 9.6000 & 1.4825 to 62.1637 \\
\hline Alleles & No. & $\%$ & No. & $\%$ & P value & OR & $(95 \% \mathrm{CI})$ \\
\hline $\mathbf{A}$ & 17 & 42.5 & 34 & 85 & \multirow{2}{*}{0.0002} & \multirow{2}{*}{7.6667} & \multirow{2}{*}{2.6281 to 22.3654} \\
\hline $\mathbf{C}$ & 23 & $\mathbf{5 7 . 5}$ & 6 & 15 & & & \\
\hline
\end{tabular}

يبين الجدول (1) مستوى المشاهدة الاليلي والنمط الوراثي للجين ATHFR في الموقع A1298C علما بان الاليل Aو الطيل الاليل الطبيعي والاليل C هو الاليل الطافر اذ اظهرت نتائج الدراسة لمجموعة النساء اللواتي يعانون من الاسقاط المتكرر بان نسبة

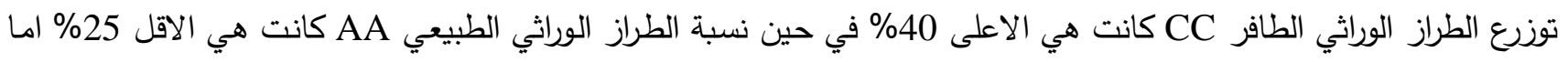

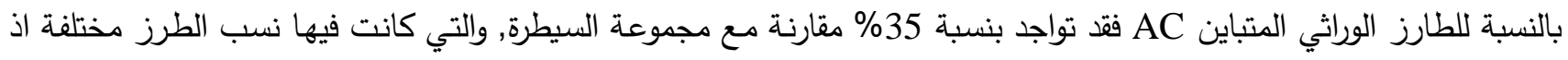

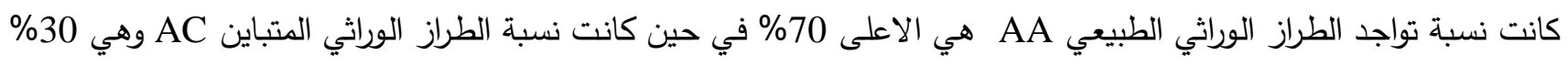
بينما لم تسجل اي ظهور للنمط الوراثي الطافر CC في مجموعة السيطرة. اما بالنسبة لمستوى المشاهدة الآليلي فقد بينت الدراسة لهذه المجموعة بان الاليل الطافر C كان مستوى المشاهدة الاليلي 57.5\% بينما الاليل الطبيعي A كان مستوى المشاهدة الاليلي 
42.5\% مقارنـة مـع مجموعـة السيطرة اذ كان مستوى المشـاهدة الاليلي للاليل الطبيعي 85\% والاليل الطافر بنسبة 15\%. وقد

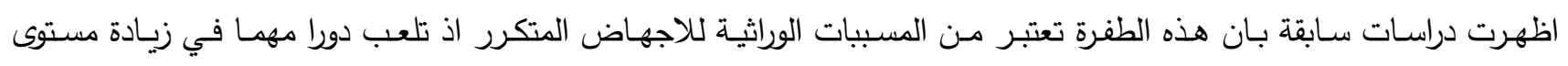

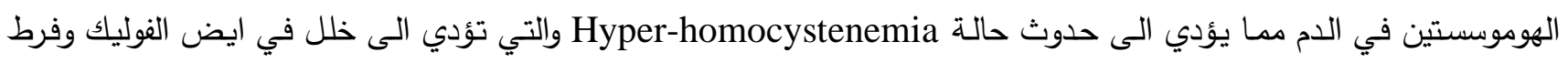
التخثر في المشيمة وبالتالي حدوث حالة الاجهاض، كذلك اظهرت نتائج الدراسة بان قيمة الـ O.R هي (9.6000) بالنسبة للطراز الوراثي الطافر CC وهذا يعتبر عامل خطورة وحدوث اضطرابات الحمل الناتجة عن خلل في عمل الجين MTHFR. وعند اجراء اختبار هاردي_وينمبرغ تبين بان قيمة PValue تساوي 0.204233 وهي اقل من 0.5 وهذا يدل بان هذه المجموعة

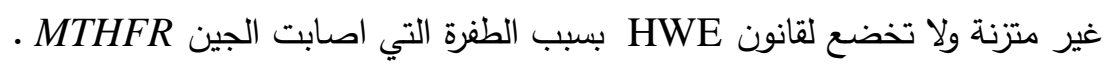
اظهرت نتائج الدراسة كما هو موضح في الثكل (2) وجود التباين الوراثي للجين ATHFR في الموقع A1298C وبجميع الطرز الوراثية AA,AC,CC لاى النساء اللواتي يعانين من حالات الجنين الميت.

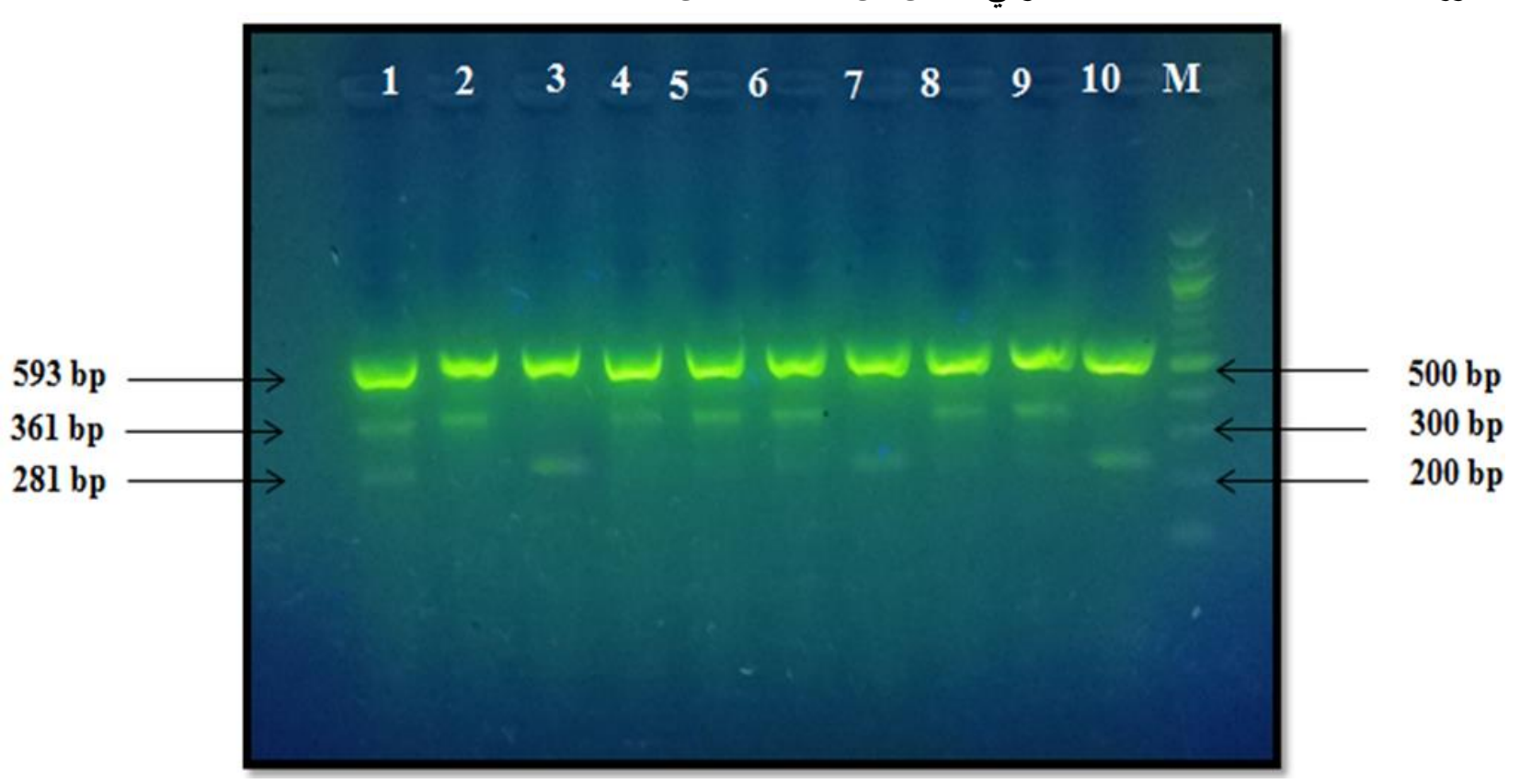

الثكل (2): تبين ناتج تفاعل الـ PCR الخاص بالتباين الوراثي للجين MTHFR (A1298C) في مجموعة النساء ذوات الجنين الميت إذ إن M تمثل الدليل

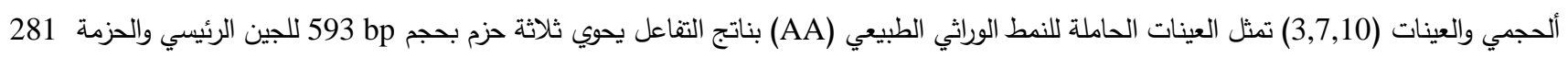

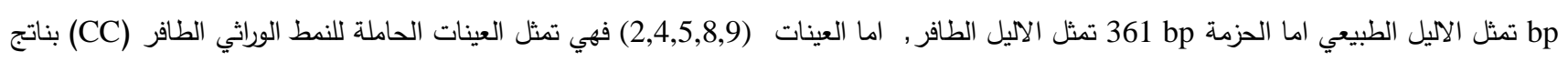

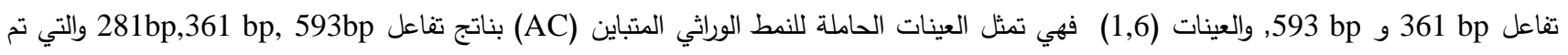
ترحيلها في هلام الاكاروز بتركيز 2\%

كما يبين الجدول (2) توزيـع النمط الوراثي للجين MTHFR في الموقع A1298C اذ اظهرت نتائج الدراسـة لمجموعة

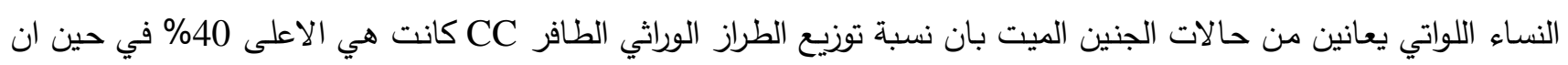

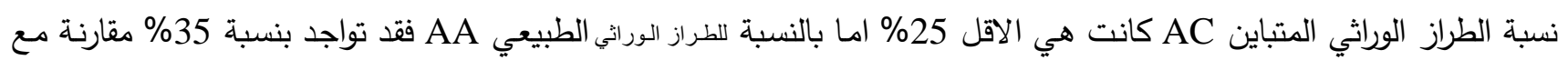

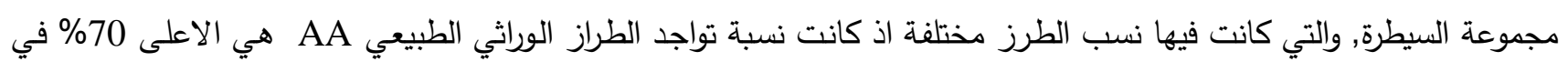

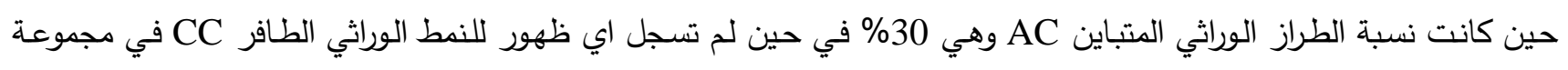

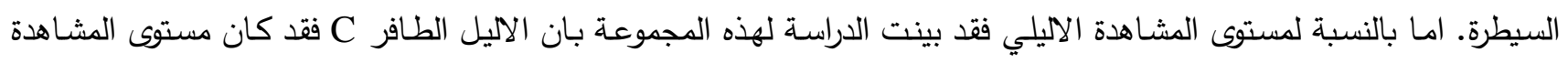


الاليلي 52.5\% في حين ان الاليل الطبيعي A فقد كان مستوى المشـاهدة الاليلي 47.5\% مقارنـة مـع مجموعة السيطرة اذ كان

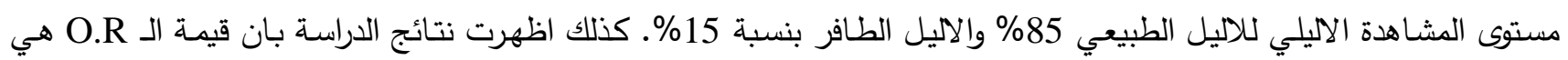
(6.8571) بالنسبة للطراز الوراثي الطافر CC وهذا يعتبر عامل خطورة وحدوث اضطرابات الحمل الناتجة عن خلل في عمل

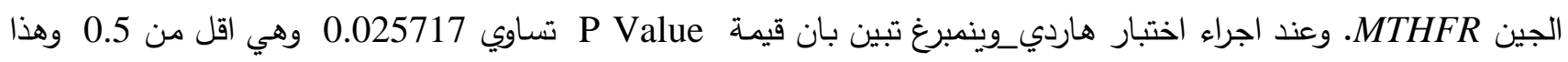

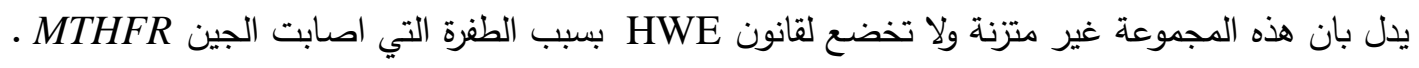

جدول (2): توزيع النمط الوراثي ومستوى المشاهدة الاليلي للجين MTHFR في الموقع (A1298C) بين مجموعة السيطرة والنساء اللواتي يعانون من حالات الجنين الميت

\begin{tabular}{|c|c|c|c|c|c|c|c|}
\hline \multirow[t]{2}{*}{ Genotypes } & \multicolumn{2}{|c|}{$\begin{array}{l}\text { Patients No. } \\
\text { (20) }\end{array}$} & \multicolumn{2}{|c|}{$\begin{array}{l}\text { Control } \\
\text { No. (20) }\end{array}$} & \multirow[t]{2}{*}{$P$ value } & \multirow[t]{2}{*}{ OR } & \multirow[t]{2}{*}{$(95 \%$ CI $)$} \\
\hline & No. & $\%$ & No. & $\%$ & & & \\
\hline AA & 7 & 35 & 14 & 70 & \multirow{3}{*}{0.5027} & Ref & \multirow{2}{*}{0.3742 to 7.4242} \\
\hline $\mathrm{AC}$ & 5 & 25 & 6 & 30 & & 1.6667 & \\
\hline $\mathrm{CC}$ & 8 & 40 & $\mathbf{0}$ & $\mathbf{0}$ & & 6.8571 & 1.1241 to 41.8289 \\
\hline Alleles & No. & $\%$ & No. & $\%$ & $P$ value & OR & $(95 \% \mathrm{CI})$ \\
\hline A & 19 & 47.5 & 34 & 85 & \multirow{2}{*}{0.0008} & \multirow{2}{*}{6.2632} & \multirow{2}{*}{2.1549 to 18.2038} \\
\hline $\mathrm{C}$ & 21 & 52.5 & 6 & 15 & & & \\
\hline
\end{tabular}

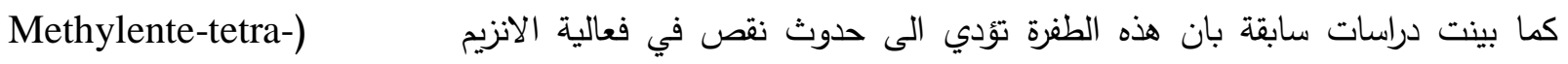
(hydrofolat-reductase المركب 5-Methylen tetra hydrofola وهو يعتبر الثكل المنتشر والسائد للفوليت، وان طفرة A1298C سجلت على انها تقلل من فعالية ونشاط الانزيم ان الاشخاص الحامليين للنمط الجيني متغايير الزيجوت يمتازون بزيادة مستوى الهوموسسين ونقصان

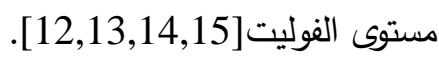
كما اظهرت نتائج الدراسة بالنسبة لمجموعة النساء ذوات فحص الـ TORCH الموجب كما هو موضح في الثكل (3) وجود التباين الوراثي للجين ATHFR في الموقع A1298C وبجميع الطرز الوراثية AA,AC,CC. 


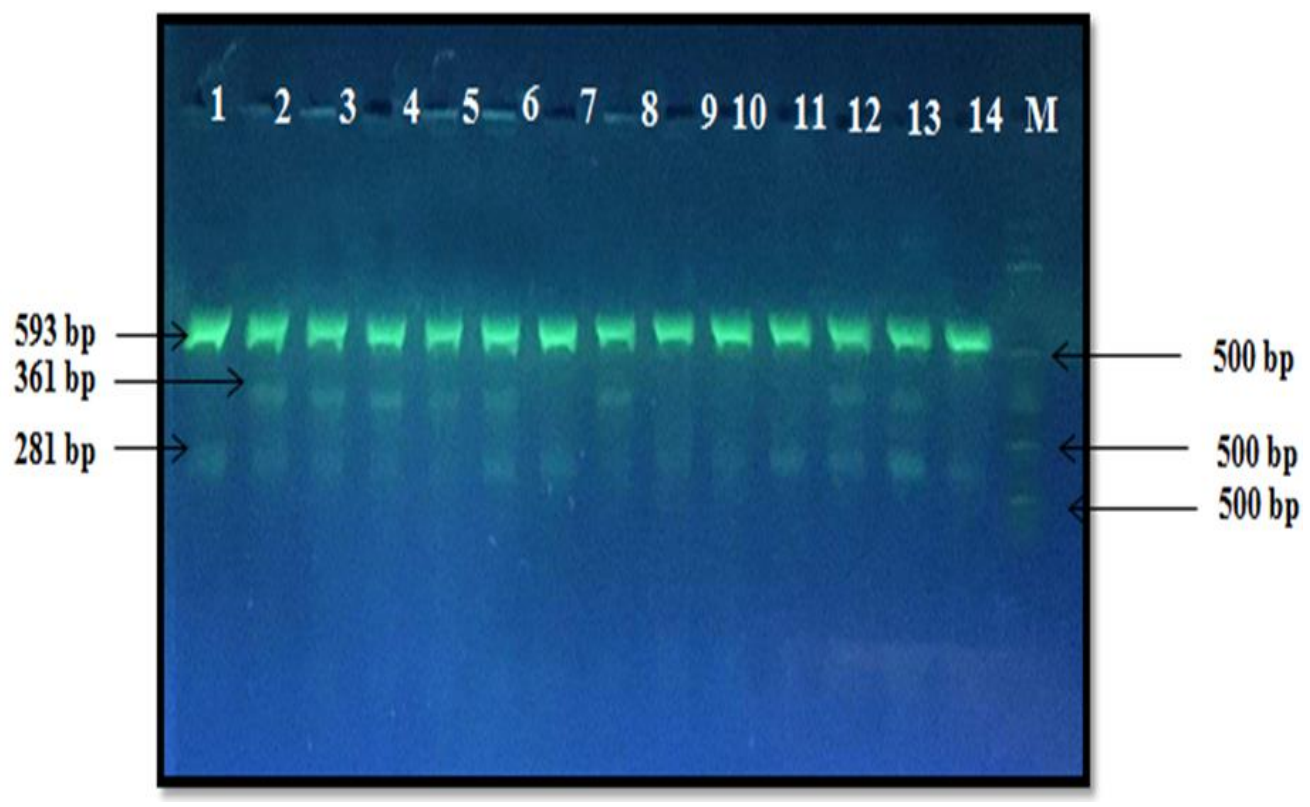

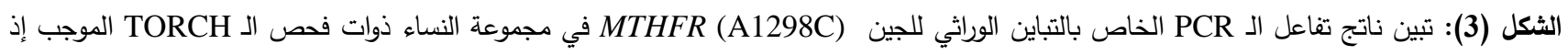
إن M تمثل الدليل ألحجمي والعينات (3) تئج

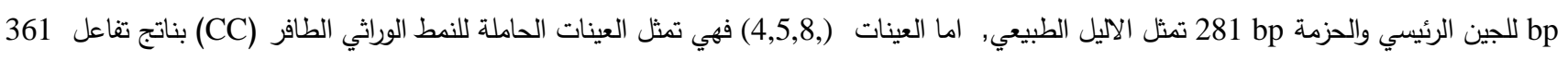

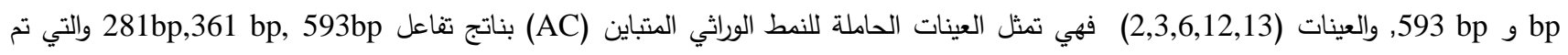
ترحيلها في هلام الاكاروز بتركيز 2\% و

ويبين الجدول (3) مستوى المشاهدة الاليلي والنمط الوراثي للجين MTHFR في الموقع A1298C اذ اظهرت نتائج الدراسة لمجموعة النساء اللواتي يعانين من فحص TORCH الموجب بان نسبة توزيع الطراز الوراثي المتباين AC هي الاعلى

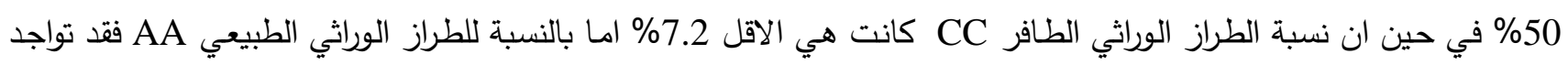

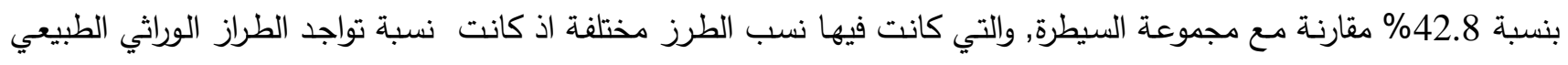

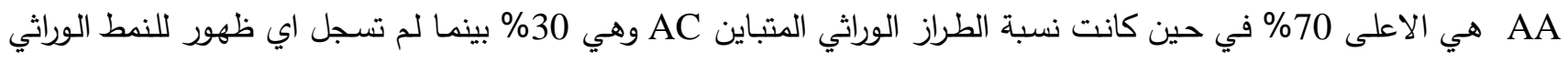

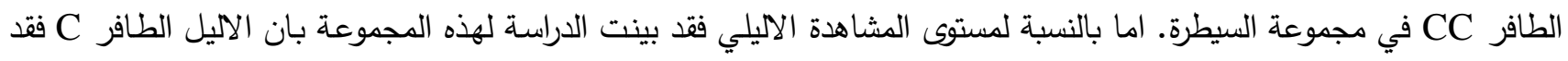

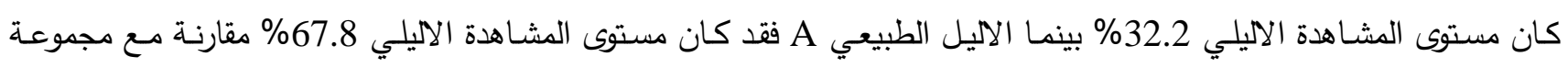

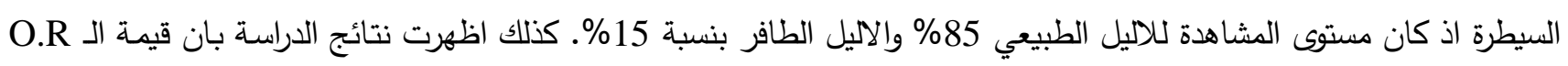

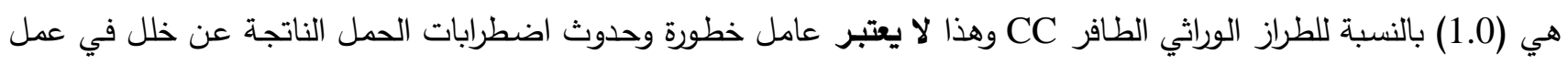

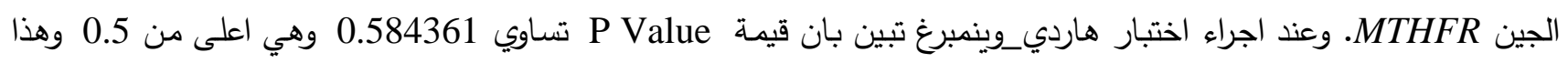
يدل بان هذه المجموعة متزنة وتخضع لقانون HWE وعنداء 
جدول(3) : توزيع النمط الوراثي ومستوى المشاهدة الاليلي للجين MTHFR في الموقع (A1298C) بين مجموعة السيطرة

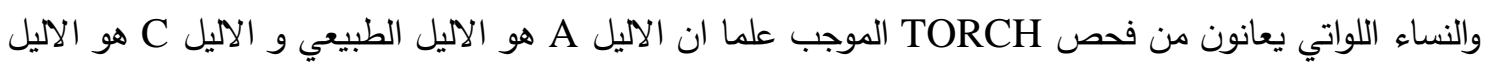

الطافر .

\begin{tabular}{|c|c|c|c|c|c|c|c|}
\hline \multirow[t]{2}{*}{ Genotypes } & \multicolumn{2}{|c|}{$\begin{array}{l}\text { Patients No. } \\
(20)\end{array}$} & \multicolumn{2}{|c|}{$\begin{array}{l}\text { Control No. } \\
\text { (20) }\end{array}$} & \multirow[t]{2}{*}{$P$ value } & \multirow[t]{2}{*}{ OR } & \multirow[t]{2}{*}{$(95 \% \mathrm{CI})$} \\
\hline & No. & $\%$ & No. & $\%$ & & & \\
\hline $\mathrm{AA}$ & 6 & 42.8 & 14 & 70 & \multirow{3}{*}{0.2634} & Ref. & \multirow{2}{*}{0.6383 to 11.6101} \\
\hline $\mathrm{AC}$ & 7 & $\mathbf{5 0 . 0}$ & 6 & 30 & & 2.7222 & \\
\hline $\mathrm{CC}$ & $\mathbf{1}$ & 7.2 & $\mathbf{0}$ & $\mathbf{0}$ & & 1.0000 & 0.0748 to 13.3676 \\
\hline Alleles & No. & $\%$ & No. & $\%$ & $P$ value & OR & $(95 \% \mathrm{CI})$ \\
\hline $\mathrm{A}$ & 19 & 67.8 & 34 & 85 & \multirow{2}{*}{0.0998} & \multirow{2}{*}{2.6842} & \multirow{2}{*}{0.8283 to 8.6980} \\
\hline $\mathrm{C}$ & 9 & 32.2 & 6 & 15 & & & \\
\hline
\end{tabular}

وقد اشارت بعض الدراسات الى ان حدوث هذه الطفرة التي تؤدي الى تغير الحامض الاميني الارجنين الى البرولين مما يؤدي الى الى تغيير في التعبيير الجيني للانزيم (Methylen tetra hydrofolate reductase ) وايضا تسبب انخفاض التوافر الحيوي للفوليت

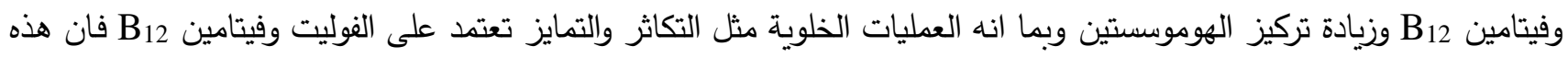
التاثيرات قد تكون واضحة بشكل خاص في مرحلة مبكرة من التطور الجنيني عندما تعاني الخلايا تكاثرا وتمايزا سريعين، وهي تعتبر

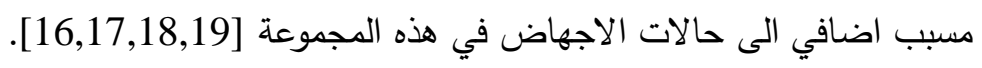
وقد اظهرت نتائج الدراسة بعد قياس متلازمات الاجسام المضادة للفوسفولبيد للجاميع الدراسة بان الفحوصات الموجبة للجم

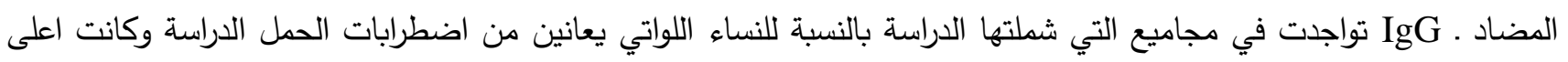

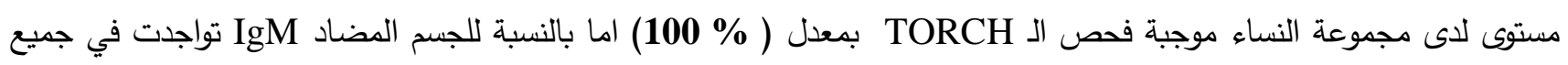
المجاميع وكانت اعلى مستوى لدى مجموعة النساء ذوات الجنين الميت بمعل ( 71\%) وكما موضح في الجدول التالي.

الجدول (4): بين نتائج مضادات Antiphospholipid للات IgG \& IgM في العينات التي شملتها الدراسة (ml U\mL)

\begin{tabular}{|l|l|l|l|l|}
\hline Antibody & RSA $(\mathrm{n}=21)$ & MIS $(\mathrm{n}=30)$ & TORCH $(\mathrm{n}=14)$ & Range \\
\hline $\mathrm{IgG}+$ & $18(85 \%)$ & $(87 \%) 26$ & $(100 \%) 14$ & $35.2-79.4$ \\
\hline IgG - & $3(15 \%)$ & $(13 \%) 4$ & ------ & $0.57-0.98$ \\
\hline IgM + & $15(71 \%)$ & $(53 \%) 16$ & $(7 \%) 1$ & $1.21-5.70$ \\
\hline IgM - & $6(29 \%)$ & $(47 \%) 14$ & ------ & $0.3-0.6$ \\
\hline
\end{tabular}

كما اظهرت نتائج الدراسة بعد قياس متلازمات الاجسام المضادة للكارديولبين لمجاميع الدراسة بان الفحوصات الموجبة للجسم

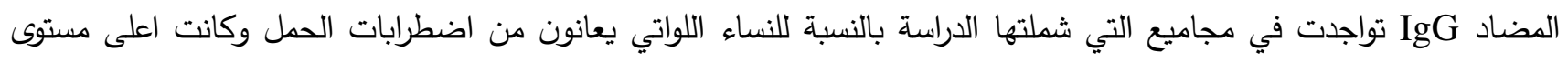

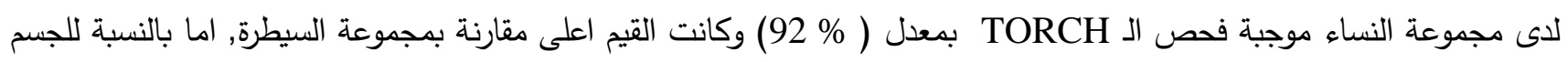

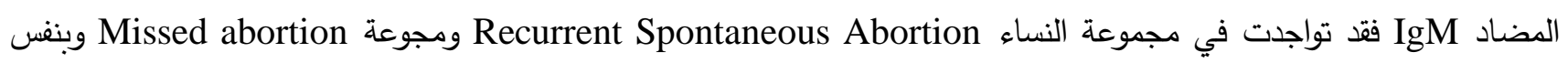
الدرجة (15\%). (15) (2) 
الجدول (5): بين نتائج مضادات Anticardiolipin للا IgG \& IgM في العينات التي شملتها الدراسة (U/mL)

\begin{tabular}{|l|l|l|l|l|}
\hline Antibody & RSA $(\mathrm{n}=21)$ & MIS $(\mathrm{n}=30)$ & TORCH $(\mathrm{n}=14)$ & Range \\
\hline IgG + & $18(85 \%)$ & $28(93 \%)$ & $13(92 \%)$ & $1.15-27.07$ \\
\hline IgG - & $3(15 \%)$ & $2(7 \%)$ & $1(8 \%)$ & $0.35-1.29$ \\
\hline IgM + & $3(15 \%)$ & $3(15 \%)$ & ------- & $1.82-9.06$ \\
\hline IgM - & $2(11 \%)$ & ------ & ------ & $0.76-0.77$ \\
\hline
\end{tabular}

اشارت دراسات عديدة الى ان هذه المتلازمة تعد اضطرابا في النظام المناعي يتميز بحدوث زيادة او فرط في تخثر الدم ومضاعفات اخرى لدى النساء الحوامل (اجهاض مبكر وولادة مبكرة وموت الجنين) ووجود اجسام مضادة لل antiphophlipid في لهدي

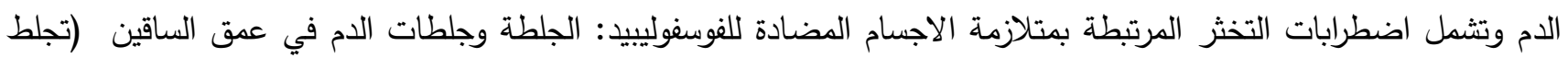

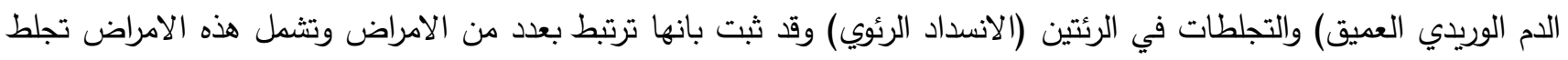

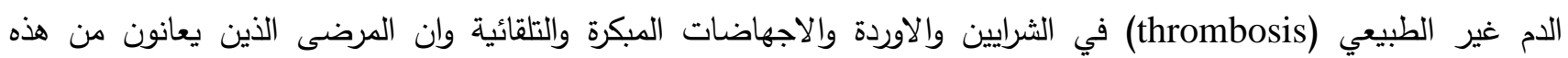
المتلازمة يحصل لديهم جلطات دموية وايضا لديهم اضداد فوسفوليبيد قابلة للكثف عن طريق فحص الدم [8,9].

نستنتج من هذه وجود علاقة بين حالات اضطرابات الحمل والطفرات الوراثية التي تصيب الجين MTHFR في الموقع A1298C. كما نستنتج بعد قياس متلازمات الاجسام المضادة للفوسفولبيد والكارديولبين ، فان النتائج الموجبة للجسم المضاد IgG تواجدت في مجاميع التي شملتها الدراسة بالنسبة للنساء اللواتي يعانين من اضطرابات الحمل وكانت اعلى مستوى لاى مجموعة النساء موجبة فحص ال TORCH.

شكر وتقدير: بعد انتهاء كل عمل يتوجب ان نتقدم بالثكر والعرفان لكل من ساعد وسهل من اتمام هذا العمل لذلك كثيرون من هم يتوجب علينا شكرهم لكننا نخص شكرنا لجامعة الموصل وكلية العلوم على اتمام هذا العمل.

المصادر

1- Chaithra, P., Malini, S. and Kumar, C. Int J Hum Genet.,11(4) : 217-225. (2011).

2- Cao, Y., Zhang, Z., Zheng, Y., Yuan, W., Wang, J., Liang, H., Chen, J., Du, J., and Shen, Y. Genes Nuter., 9(3) :1-8. (2014).

3- Daniel, V. Biomed J., 37(4): 1-14.(2015).

4- Aly, R., Taalab, M., Ghazy. HInternational journal of clinical and experimental pathology, 7:2571. (2014). 
5- Huo, Y., Li, J., Qin, X., Huang, Y., Wang, X., Gottesman, R., Tang, G., Wang, B., Chen, D., He, M., Fu, J., Cai, Y., Shi, X., Zhang, Y., Cui, Y., Sun, N., LI, X., Cheng, X., Wang, J., Yang, X., Yang, T., Xiao, C., Zhao, G., Dong, Q., Zhu, D., Wang, X., Ge, J., Zhao, L., Hu, D., Liu, L. and Hou, F. JAMA, 313:1325-35. (2015).

6- Wang, X., Fu, J., Li, Q. and Zeng, D. Geographical and ethnic distributions of the MTHFR C677T, A1298C and MTRR A66G gene polymorphisms in Chinese populations: a metaanalysis. PLoS ONE, 11:e0152414. (2016).

7- Negin, J., Mohammad, H., Ali, A. Electron J Gen Med., 15(4):2516-3507.(2018).

8- Michel, T., Ali, D., Robert, D., Eric, L., Lilach, O. and Amir, L. J Am Coll Cardiol., 69(18) :2317-30. (2017).

9- Jahromi, A., Farjam, M., Mogharrab, F., Amiryam, M. and Makiani, M. Am. J. Infect. Dis., 6: 66-69. (2010).

10- Iranpur, V. and Esmailizadeh, A. JBM Journal of Biological Methods. (2010)

11-Sahel, T., Taher, M. and Hossein, R. Obstet Gynecol Int J., 8(2):1-6. (2017).

12-Cortese, C. and Motti, C. Public Health Nutr., 4:493-7. (2001).

13-Crider, K., Zhu, J., Hao, L., Yang, Q., Yang, T., Gindler, J., Maneval, D., Quinlivan, E., Li, Z., Bailey, L., and Berry, R. Am J Clin Nutr., 93:1365-72. (2011).

14-Sheikhha, M., Kalantar, S., Ghasemi, N. and Soleimanian, S. Iran J Pediatr Hematol Oncol., 2(3):109-13. (2012).

15-Zhu, B., Xiahou, Z., Zhao, H., Peng, B., Zhao, H. and Xu, X. Biochemical and biophysical research communications ,447:702-706. (2014).

16-Wong, C. Hong Kong Med J., 21:155-64. (2015).

17-Chandran, J., Anderson, G., Kennedy, A., Kohn, M. and Clarke, S. Int J Eat Disord., 48:1176-9. (2015). 
18-Nakamura, T., Nishi, M., Rikitake, M., Koga, D., Eto, J., Tajima, D., Toda, S., and Matsuo, M. Brain Dev., 41(11) :1-5. (2018).

19-Zhang, X., Hou, C., Liu, P., Chen, L., Liu, Y., Tang, P. and Li, R. Front. Neurol., 9:1162. (2019). 